\title{
Use of Problems in a Didactic Embryology Course: Outcome
}

\author{
Dutta, $S^{1} \&$ Saxena, $S . K^{2}$
}

\begin{abstract}
Background: Problem based learning (PBL)was being implemented in medical schools since 1950 but there was a debate among the medical teachers regarding the outcome of the PBL in concern to basic science knowledge.
\end{abstract}

Aim of the study: The present study was aimed to evaluate various merits and demerits of the didactic lecture (DL) and PBL in the field of medical education and to motivate novice for self-directed learning

Material and methods: There was separate PBL session in addition to their routine scheduled lectures. At the end of experiment students were interviewed and given Likert's type close ended Questionnaire to express their opinion.

Result: Students were in the opinion that trivial detailed should be avoided to teach basic science subjects. They had mention that PBL was good for small group discussion, clinical correlations, exchange of ideas self-directed learning and critical thinking skill. Majority of them expressed needs, guidance from teachers to learn, a complex subject like embryology and didactic lectures helps them to know the, depth of a particular topic. Students had mentioned that they did not learn basic concept of the particular topic by PBL. Therefore, they expressed that PBL session should be conducted after $\mathrm{DL}$.

Conclusion: PBL can be implemented in small group, to improve the communication skill, critical thinking even in the conventional curricular medical schools but DL cannot be replaced by PBL. Therefore, hybrid problem based learning (HPBL) will be a better strategy to learn basic science subjects.

Key words: Didactic lecture, Problem based learning, Hybrid problem based learning, Teachinglearning strategies, Triangulation, Focus group

\section{Introduction}

The aim of the conventional curriculum is to expose all students to the identical knowledge, and develop same interests by didactic lecture (DL) (Finch, 1999). The core concept of the conventional medical school is the firm foundation of the basic science knowledge before entering into clinical practice (Dutta 2010). Therefore organization of traditional curriculum is discipline based and each discipline has its own logical structure and sequence (Phil, 2000).

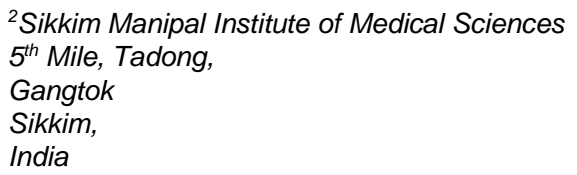

Corresponding Author:

${ }^{1} D r$. Dutta,S.

Professor of Anatomy

Mayo Institute of Medical Sciences

Barabanki,

Lucknow,

India

E Mail:dutta8suk@hotmail.com 
The significant area of the conventional curriculum is instructor provided learning objectives and assignments, large group didactic lectures, structured laboratory experiences (Nandi et al, 2000).

There was a perception that the traditional method of study will provide a solid foundation for the subsequent clinical study but the relevance and applicability of it soon lost (Miller, 1962).Moreover, often students mention that $\mathrm{DL}$ is a passive and boring method of learning process (Nandi et al, 2000) because it is a one way learning process (Abdul, 1999). Therefore it becomes ineffective in concern to knowledge retention and students satisfaction (Sandhu et al, 2012). To overcome this situation, a number of educationists attempted something new and came out with problem-based learning.

The PBL is an active educational process and focused around a clinical, community or scientific problems (Nandi et al, 2000). The fundamental concept of PBL is to promote critical thinking, time-management skills, and self-organizational competences by exposing to real-life situations which is relevant to their future professional activities (Botelho and O'Donnell, 2001). Moreover it is more nurturing, enjoyable and humanistic approach of learning process in comparison with the didactic lectures (Huang 2005). Hence students are less stressed and that increases the retention of gained knowledge than their counterpart of the traditional schools (Dolmans and Schmidt, 1996). In contrast to traditional method, students actively learn for themselves by using the given problems, which act as a stimulus for their learning. Therefore students demonstrate superior professional competence as compared with their counter part of traditional curricula (Neville, 2009). Bernstein et al, 1995 mentioned that students rated better for acquiring knowledge in the traditional methods and PBL is better for improving teamwork and doctorpatient relationship.

The students of the PBL curriculum do not learn basic science subjects in depth because they learn the basic science knowledge in clinical context (Abdul et al, 1999; Nandi et al, 2000). Therefore students of PBL curriculum scored lower on basic science examinations in comparison with their conventionally trained counterparts (Albanese and Susan, 1993; Nandi et al, 2000)..

There was a controversy about the result outcome of the innovative PBL, especially in concern to basic sciences knowledge. In the extensive review of literature was been observed that both DL and PBLwere having some merits and demerits. In the recent past, most of the educationists of the field of medical education believe that it was better to combine the positive aspects of the both teachinglearning strategies (Nandi et al, 2000; Ghosh 2007; Carrio et al, 2011).

The present study was aimed to evaluate various merits and demerits of the didactic lecture (DL) and PBL in the field of medical education and to motivate novice for selfdirected learning.

\section{Material and methods}

\section{Research experiment design}

The present research experiment was conduct on PBL. Investigators obtained written permission from the Dean, Sikkim Manipal Institute of Medical Sciences, Sikkim, India before commencement of the experiment. The students were informed regardingthe purpose of the study. It was not mandatory for the students to attend the experimental classes. There were hundred students in the concern batch. The whole batch had undergone the PBL sessions throughout their first year of the basic science as Anatomy is taught in the first year of their curriculum. The primary investigator gave an introduction about the process of problem based learning before commencement of the sessions because students were not having any earlier exposure to the PBL.

The basic outline of PBL process followed seven criterias, suggested by the Dolmans et al (1997):

Entire batch was made into five small groups. Each group again subdivided into four subgroups. Therefore each subgroup was comprised of 4-5 students.

Encountering the problem: Each group was provided with a clinical problem related to human development.

Problem solving: Students used to discuss and analyse the clinical problems and also clarified their unknown areas in presence of researcher (facilitator/teacher) and need to come out to a common perception and/or insight of the problem at the end of session. In the process of discussion unknown areas were identified and pointed as "learning issues" that serves as a guide for independent and self-directed learning. Through this process novice tried to 
understand the underlying principles of the topic of concerned.

Self-study: Students prioritize the learning objective and had choices about the resources (i.e. text books, journals, Internet, videotape, lectures, and peers). Their objective was to address the learning issues in sufficient depth.

Applying newly gained knowledge to the problem: Each group was asked to meet the researcher once a week to discuss the given clinical problem. Students were advised to emphasize the basic concept of the concern topic.

Summarizing and evaluation: At the end of each session students summarized their learning issues. Each member of the group including the facilitator (researcher) evaluates their role in the process of PBL. A positive feedback was given to the members with the suggestion to improve the exercise.

\section{Questionnaire survey}

Questionnaire was prepared as per the guidance suggested by the Abramson \& Abramson, 1999. Students were given Likert's scale, close ended questionnaire with three responses at the end of the experiment. A total number of ninety-three questionnaires were distributed and ninety-two questionnaires were returned with the responses. Students were advised not to disclose their identity, to avoid the bias of the investigator.

\section{ResultS}

Interview survey

Primary investigator conducted all the interviews to avoid any misinterpretation. The interviewees of the current research were the students of the focused (experimental) group (Powell and Single, 1996). Students were interviewed in the investigator's office, in the hostel corridor and/or in the canteen (student's mess) whenever they were found in stress free. The duration of the interview for each respondent varied from thirty minutes to one hour according to availability of time. All the ninety three students were not interviewed due to the "issue saturation" (Glaser and Straus, 1967). All the seven stages of interview were followed as described by Kvale Steiner (1996).

To overcome the subjective nature of the experiment and to validate the collected data, triangulation methodology is applied in the current research (Weyers et al, 2011). The data collected by the questionnaire was corroborated with the focused group interview

Ethical committee permission and financial obligation: Our study was not required to get ethical committee permission nor was having any financial obligation to any organization or institution.

Table - 1: Opinions of the experimental group of the students $(n=92)$

Opinions

Didactic lecture is very interesting way to learn embryology

$05 \%$

$96 \%$

Didactic lecture is useful to understand a topic of embryology

Proper guidance is provided by the teacher in didactic lecture

Can exchange valuable ideas in didactic lecture class

Learn basic concept of the particular topic in the PBL session
Percentage 
Teacher guidance was helpful for the PBL session

PBL session is useful to understand a topic of embryology

Can exchange valuable ideas in the PBL session

Clinical condition can be better related by virtue of PBL sessions

I spend more time and learn less in PBL session

$70 \%$

PBL sessions should be followed by didactic lecture

\section{Interview Survey}

Table- 2: Students of the experimental group of the conventional school $(n=50)$

\begin{tabular}{|c|c|c|}
\hline System & Merits & Demerits \\
\hline \multirow[t]{3}{*}{ Conventional } & $\begin{array}{l}\text { - Teacher guidance } \\
\text { - Three basic science subjects in the } \\
\text { first year i.e. Anatomy, Physiology and } \\
\text { Biochemistry } \\
\text { - Lecture plays significant role to } \\
\text { understand the subject }\end{array}$ & $\begin{array}{l}\text { - } \\
\text { - } \quad \text { Lack of small group discussion } \\
\text { - } \quad \text { Lack of clinical orientation } \\
\text { - } \quad \text { No opportunity to clarify the doubts in the } \\
\text { - } \quad \text { lecture class for every individuals } \\
\text { Passive learning process }\end{array}$ \\
\hline & Merits & Demerits \\
\hline & $\begin{array}{l}\text { - } \quad \text { Clinical case oriented learning } \\
\text { - } \quad \text { Small group learning } \\
\text { - } \quad \text { Self-directed learning } \\
\text { Interesting way to learn the subject }\end{array}$ & $\begin{array}{l}\text { - Lack of teacher guidance } \\
\text { - Difficult to get the basic concept } \\
\text { - } \quad \text { All aspects of embryology is difficult to } \\
\text { learn }\end{array}$ \\
\hline
\end{tabular}

\section{Suggestions}

- Avoid trivial detail

- Early exposure to the patient

- Small group discussion after lecture class along with the models and/or multimedia

- Related embryology should be taught along with the specified topic of the gross anatomy

- Lecture should be principle component to teach and learn embryology

- Related health problem should be given at the end of the lecture class of the specific topic and call for small group discussion

\section{Discussions}

Teacher transfers the information from the literature to the students by the didactic lectures, in the traditional school. Therefore 
students and teachers are not equally responsible in this process (Abdul, 1999). As a result, students are passively involved in the learning process (Nandi et al, 2000), which are reflected in our study result as $5 \%$ were in the opinion that DL was very interesting module to learn embryology and $46 \%$ were in the opinion they get proper guidance by the teacher in the DL class because most of them can not clear their doubts at the end of the lecture session due to large number of students which was expressed in the interview. Therefore, $34 \%$ of them mentioned that they got an opportunity to exchange their ideas. Moreover in the interview, they expressed that DL was a oneway of passive learning process and sometime becomes 'boring" that agreed with Abdul, 1999; Nandi et al, 2000; Peter, 2001; Huang, 2005; Dutta 2010. Whereas $96 \%$ mentioned DL was required to understand a topic of embryology and that had been reflected in the interview survey which agreed with Botelho and O'Donnell, 2001; Nandi et al, 2000; Ghosh,2007.

In the present study $74 \%$ of the students were in the opinion that PBL was useful to understand a topic of embryology. But in the interview students mentioned that they did not learn basic concept of the particular topic of the given case and same opinion was expressed in the questionnaire survey as $30 \%$ of them mentioned that they learned basic concept by the PBL approach that agrees with Patel et al, 1991; Albanese and Susan,1993; Abdul et al, 1999; Nandi et al, 2000 and Huang, 2005.

$98 \%$ mentioned they got guidance by the teacher in the PBL session as it was a small group teaching and an active learning process which agrees with Botelho and O'Donnell, 2001;Huang, 2005; Saleh1 et al ,2013. But in the interview they expressed the lack of direct teachers' guidance because in this process teacher acts as a facilitator which agrees with O'Hanlon et al, 1995; Huang, 2005. Therefore, it was difficult to learn the basic concept of the topic which agreed with O'Hanlon et al, 1995. Students were in the opinion that to learn complex subject like embryology teachers' guidance was essential, which agreed with Bernstein et al, 1995; Botelho and O'Donnell, 2001. Hence DL can't be replaced by the PBL. Therefore till date lecture remains as an important component even in PBL curriculum (Malik \& Malik, 2012).

$90 \%$ of them mentioned that they can exchange their valuable ideas with peer members and facilitator which agreed with the earlier workers done by Botelho and O'Donnell, 2001; Huang, 2005; Saleh1 et al 2013. Another positive aspect of PBL was being expressed by the $95 \%$ novice that basic science knowledge can be correlated with the clinical context that agrees with Barman et al, 2006; Nandi et al, 2000; Ghosh,2007.

In the present case study school students were not having any earlier experience of selfdirected learning. Therefore were uncertain about the literature survey and tended to go beyond the learning issues which had been reflected as $74 \%$ of the students expressed they spent more time and learn less in the PBL sessions, agreed with O'Hanlon et al, 1995; Hurk et al, 1999; Huang, 2005.

In the interview survey students had mentioned the negative aspects of their school includes lack of self-directed learning, clinical orientation and small group discussion whereas they preferred PBL, in concern to small group, selfdirected learning, critical thinking and most important was clinical orientation which agrees with Bernstein et al, 1995 ; Dolmans and Schmidt, 1996; Carrio et al, 2011. Moreover, they were in the opinion for the early exposure to the patient which agreed with Miflin et al (2000).

Present study result suggests the mixture of the both teaching-learning strategies will be superior because there were unanimous opinion to continue the PBL to get the merits of it and $70 \%$ of them were in the opinion that PBL sessions should be followed by the DL of a particular topic of the concern subject which agrees with the Nandi et al, 2000; Ghosh, 2007; Carrioet et al, 2011.

\section{Conclusion}

Our study finding suggests that didactic lecture is essential to guide the novice to learn a basic science subject. Clinical significance of a topic must be taught along with basic science to know the importance of that particular topic in clinical science. Some opportunity should exist for earlier exposure to the patients for their motivation to learn the basic science knowledge. Novice must get an opportunity for self-directed learning, critical thinking skill and small group discussion. Therefore a mixture of didactic lecture and problem based learning will be a better teaching-learning strategy for the basic science subjects. It is important to adopt a humanistic approach to teach basic science subjects to avoid the monotony of the didactic lecture. 


\section{Reference:}

Abdul-Ghaffar, T. A., Lukowiak, K. \& UshaNayar. (1999) Challenges of teaching physiology in a PBL School. Am J Physiol. 277 Adv Physiol Educ 22), pp.140-147.

Abramson, J.H., \& Abramson, Z.H. (1999) Survey method in community medicine. Epidomiological research, Program and evaluation, Clinical trials. $5^{\text {th }}$ Eds. Churchill Livingstone.Printed in China.

Albanese, M.A.\&Mitchell,S.(1993).Problem-based learning: a review of literature on its outcomes and implementation issues. Academic Medicine, 68, pp. 52-81.

Barman, A., Jaafar, R., Naing, N. N.(2006) Perception of students about the problem-based learning sessions conducted for medical and dental schools' students of University Sains Malaysia. Education for Health, 19(3), pp.363-368.

Dolmans, D. H. J. M., Snellen-Balendong, H., Wolfhagen, I.H.A.P.\& Van Der Vleuten, C. M. P. (1997) Seven principles of effective case design for a problem-base curriculum. Medical Teacher, 19, pp.185-189.

Dutta, S. (2010) Conventional Teaching in Basic Science: An inner view. Al Ameen Journal of Medical Sciences, 3(3), pp.246-250.

Finch, P.M. (1999) The effect of problem-based learning on the academic performance of students studying podiatric medicine in Ontario. Medical Education; 33:pp. 411-417.

Ghosh, S. (2007) Combination of didactic lectures and case-oriented problem-solving tutorials toward better learning: perceptions of students from a conventional medical curriculum. Adv.Physiol.Educ. 31(2):pp193-197.

Glaser, B.\& Strauss, A.L. (1967) The discovery of grounded theory: strategies for qualitative research. Aldine, Chicago.

Huang, R. (2005) Chinese International Students' perceptions of the problem-based learning experience. ;4(2):pp.36-43.

Hurk, M.M.V.D., Wolfhagen, I.H.A.P., Dolmans, D.H.J.M.\&Vleuten, C.P.M.V.D. (1999) The impact of student generated learning issues on individual
Bernstein, P., Tipping, J., Bercovitz, K. \& Skinner, H. A. (1995) Shifting students and faculty to a PBL curriculum: Attitudes changed and lessons learned. Academic Medicine, 70, pp.245-247.

Botelho, M. G. \& O'Donnell, D. (2001) Assessment of the use of problem-orientated, small-group discussion for learning of a fixed prosthodontic, simulation laboratory course. British Dental Journal, 191, pp. 630-636.

Carrio, M., Larramona, P., Baños, J. E. \& Pérez. (2011) The effectiveness of the hybrid problembased learning approach in the teaching of biology: a comparison with lecture-based learning. Journal of Biological Education, 45 (4), pp. 229235.

Dolmans, D. \& Schmidt, H. (1996) The advantages of problem-based curricula. Postgrad Medical Journal, 72, pp.535-538.

study time and academic achievement. Medical.Education; 33:pp. 808-814.

Kvale Steiner (1996) Interview - an introduction to qualitative research interviewing. Thousand Oaks: Sage Publications.

Malik, A. S. \& Malik, R. H. (2012) Twelve tips for effective lecturing in a PBL curriculum. Medical Teacher, 34(3), pp.198-204.

Miflin, B., Campbell, C. B. \& Price, D. A, (2000) A conceptual frame work to guide the development of self-directed, lifelong learning in problem-based medical curriculum. Medical Education, 34, pp. 299-306.

Miller, G.E. (1962). An enquiry into medical teaching. Medical Education, 37, pp.185 - 191.

Nandi, P.L., Chan, J.N.F., Chan, C.P.K., Chan, P., Chan, L.P.K. (2000) Undergraduate medical education: comparison of problem-based learning and conventional teaching. HKMJ, 6, pp301-306.

Neville, A.J. (2009) Problem - Based Learning and Medical Education Forty Years On. A Review of Its Effects on Knowledge and Clinical Performance. Medical Principles and Practice, 18, pp 1- 9.

O'Hanlon, A., Winefield, H., Hejka, E. \& ChurHansen, A. (1995) Initial responses of first-year 
medical students to problem-based learning in a behavioral science course: role of language background and course content. Medical Education, 29, pp. 198-204.

Patel, V.L., Georen, G. J. \& Norman, G.R. (1991) Effects of conventional and problem-based medical curricula on problem solving. Academic Medicine, 66, pp.380-389.

Peter,M.C.Crorie. (2001) Tales from tooting: reflection on the first year of the MBBS graduate entry programme at St. George's Hospital Medical School. Medical Education, 35, pp. 1144-1149.

Phil \& Race (2000) Task-based learning. Medical Education, 34, pp.335-336
Powell, R.A. \& Single,H.M .(1996) 'Focus groups'. International Journal of Quality in Health Care. 8(5): pp.499-504.

Saleh. M., Al-Tawil, A., Namir, G. \& Al-Hadithi, T. (2013) Didactic Lectures and Interactive Sessions in Small Groups: A Comparative Study among Undergraduate Students in Hawler College of Medicine. British Journal of Education, Society \& Behavioural Science, 3(2), pp. 144-153.

Sandhu, S., Afifi, T.O. \& Amara, F.M. (2012) Theories and Practical Steps for Delivering Effective Lectures. Journal of community medicine \& health education, 2, pp.158

Weyers, Michae. L. L., Strydom \& Arnel, H. (2011) 'Triangulation insocial work research: the theory and examples of its practical application',Social Work/ Maatskaplike Werk, 44: 2, pp.207-222. 